\title{
General Design of the Layout for the Advanced Photon Source Beamline Front Ends
}

\author{
D. Shu and T. M. Kuzay \\ Experimental Facilities Division
}

\author{
DISCLAIMER
}

This report was prepared as an account of work sponsored by an agency of the United States Government. Neither the United States Government nor any agency thereof, nor any of their employees, makes any warranty, express or implied, or assumes any legal liability or responsibility for the accuracy, completeness, or usefulness of any information, apparatus, product, or process disclosed, or represents that its use would not infringe privately owned rights. Reference herein to any specific commercial product, process, or service by trade name, trademark, manufacturer, or otherwise does not necessarily constitute or imply its endorsement, recommendation, or favoring by the United States Government or any agency thereof. The views and opinions of authors expressed herein do not necessarily state or reflect those of the United States Government or any agency thereof.

\section{October 5, 1993}

\section{Advanced Photon Source Argonne National Laboratory}




\section{DISCLAIMER}

Portions of this document may be illegible in electronic image products. Images are produced from the best available original document. 
General Design of the Layout for the Advanced Photon Source

Beamline Front Ends

Deming Shu and Tuncer M. Kuzay

Experimental Facilities Division

Advanced Photon Source

Argonne National Laboratory

Argonne, IL 60439

\begin{abstract}
In the first phase of construction, sixteen insertion device beamline front ends and sixteen bending magnet beamline front ends will be built by 1995 for the Advanced Photon Source (APS). Designs for these front ends have been completed. In this paper, the particular designs and specifications as well as the optical and bremsstrahlung ray-tracing analysis for the APS front ends are presented.
\end{abstract}

1. Introduction

The 7-GeV Advanced Photon Source (APS) now under construction at Argonne National Laboratory is one of a new generation of synchrotron radiation sources, which have presented a multitude of design challenges in the beamline front ends. The design solutions have led to many novel and advanced features such as enhanced heat transfer concepts in the fixed masks and the photon shutters, an integral UHV collimator/safety shutter design, a submicron-resolution beam position monitor for the beam stabilization feedback system, and minimal 
beam filtering concepts to deliver maximized beam power and spectra to the experimental stations.

From the beginning of 1991 until the present time, following the completion of the APS front end conceptual design [1], a series of standardized front end components and supports were designed and reviewed [2][3]. Prototypes of the key elements, such as high heat flux photon absorber and beam position monitor were built and tested [4][5]. At the same time, the general layout design for the APS front ends was also being finalized for a construction version. Optical apertures in the front ends have been studied by the ray-tracing program SHADOW [6] under various particle beam missteering conditions. The optical raytracing also helps in the study of the various photon desorption outgassing conditions in the front end vacuum system [7]. To optimize the front end radiation shielding design, a bremsstrahlung radiation ray-tracing study has also been done.

In the first phase of construction, sixteen insertion device (ID) beamline front ends and sixteen bending magnet (BM) beamline front ends will be built by 1995. These front ends will be operated at $7-\mathrm{GeV}$ and $100-\mathrm{mA}$ positron beam current.

\section{Beamline Front Ends for APS Insertion Device (ID) Sources}

For the first phase of construction, two typical insertion devices will be installed: (1) a 2.4-meter-long 3.3-cm period Undulator A, which, at a closed gap of $11.5 \mathrm{~mm}$, will provide $3.8-\mathrm{kW}$ total power with $469 \mathrm{~W} / \mathrm{mm}^{2}$ peak heat flux at the location of the first photon shutter, and (2) a $2.4-$ meter-long $8.5-\mathrm{cm}$ period Wiggler A, which, at a closed gap of $21 \mathrm{~mm}$, will generate $7.4 \mathrm{~kW}$ total power with $223 \mathrm{~W} / \mathrm{mm}^{2}$ peak heat flux at the location of the first photon shutter[8][9].

Figure 1 shows the APS ID front end functional schematic: two fixed masks 
confine the photon beam and protect the downstream components from a missteered beam. Two "hockey-stick" style high-heat-flux photon shutters intercept the photon beam and protect the safety shutters and vacuum valves from any thermal load. Two lead collimators and two tungsten safety shutters provide radiation protection in the downstream experimental area. The photoelectron emission signals from two photon beam position monitors are fed back into the storage ring orbit control system to stabilize the photon beam. A set of filters and windows or a differential pumping system isolate the beamline vacuum from the front end vacuum. Figure 1 (a) presents the set points for the APS front end vacuum protection system.

Photon shutter 2 and the safety shutters are major front end components that are operated by the user to control the beam. Photon shutter 2 is also backed up by photon shutter 1 to provide redundancy in personal safety. In the design for the second phase of operations, photon shutter 1 is planned to act as a fast shutter that can stop the high-heat-flux photon beam thus protecting the fast valve and the slow valve without the need to dump the particle beam.

There have been several major design changes from the conceptual version to the final construction version for the APS insertion device (ID) front end. As shown in Fig. 2, the first fixed mask and photon shutter 1 now share the same support table to simplify the alignment. The first lead collimator is now mounted together with the slow and the fast valve. In the process, the fixed mask apertures were adjusted to suit these changes. Figure 3 shows the present APS ID front end optical aperture design with maximum wiggler beam missteering, in which the origin of the wiggler beam is assumed to be at the origin of the ID straight section.

For reasons of economy, we have also designed two special components (a first fixed mask and a second photon beam position monitor) for those front ends that will only use undulators as their insertion devices. In these cases, the first 
fixed mask and the second photon beam position monitor have smaller horizontal apertures. Figure 4 shows the optical aperture design for undulator-only front ends.

In the first phase of APS construction, the window will be used only for the wiggler front ends. The undulator or undulator/wiggler compatible front ends are designed to operate in a windowless configuration. An APS prototype differential pumping system with $78 \mathrm{~mm} \times 14 \mathrm{~mm}$ aperture has been designed and tested. It has achieved nearly a three decade vacuum pressure difference. Figure 5 shows the APS ID front end general layout in the windowless mode.

To optimize the front end bremsstrahlung radiation shielding in a limited space, an integral safety shutter/collimator has been designed, and a prototype has been built [10]. The shutter block, made of special UHV-compatible machinable tungsten alloy, consists of two parts. The smaller upper part is raised and lowered into the fixed lower part to provide collimation in the raised position and complete shuttering in the lowered position, respectively. The bremsstrahlung radiation ray-tracing schematic for the APS ID front end is shown in Fig. 6.

The support system for the APS ID front end is standardized. In the ID front end, there are three motorized support tables: two adjustable tables with three motions for photon beam position monitors and one adjustable table with five motions for the second fixed mask and photon shutter. The other tables are manually adjustable with mechanical counters. Fiducial holes, as well as reference surfaces, are provided in table constructions to simplify the alignment process using a laser system.

3. Beamline Front Ends for the APS Bending Magnet (BM) Sources

The APS BM front ends are designed in such a way that the photon shutters 
and fixed masks can tolerate large thermal loads and heat fluxes far exceeding even those produced during future operations at $300-\mathrm{mA}$ current of the $7-\mathrm{GeV}$ ring [11]. In this final construction version, an extra fixed mask was arranged on the BM front end at about nine meters from the source to accept a large horizontal beam missteering (up to $14 \mathrm{mrad}$ total), which is required by the storage ring in the early phases of the operation. Otherwise, the BM front end is designed to deliver a 6-mrad total horizontal radiation fan to the users labout $1.5 \mathrm{~kW}$ total photon beam power at $7 \mathrm{GeV}, 300 \mathrm{~mA}$ ).

As is seen in Fig. 7, the funtion and operation of the BM front end is similar to that of the ID front end. Figure 8 shows the APS BM front end general layout. To reduce the downstream horizontal bremsstrahlung radiation fan, two lead shielding blocks are located on the inboard side of the delay line and the second photon shutter.

\section{Discussion}

Designs for the two standard front ends, one for ID beamlines and another for BM beamlines, for the first phase of the APS project have been completed. At the time of this report, the components for these front ends are in the procurement process. These designs have incorporated novel features to handle the highest heat flux imposed on components by the brightest $x$-ray source built in the world to date. Use of grazing angle geometry in fixed masks and photon shutters coupled with a unique heat transfer technique and extensive use of Glid-Cop copper on beam exposed surfaces can meet the severe thermo-mechanical problems in these components. In the beam position monitors, the use of diamond material has solved the thermal problem of the blades while maintaining the required precision. The windowless operation afforded by a specially designed 
differential pump on the front end obviates the thermal problems of filters and windows under a closed-gap undulator beam that imposes better than 300 $\mathrm{W} / \mathrm{mm}^{2}$ heat flux on these components.

While the first phase problems of the APS beamline front ends have been adequately addressed as outlined above, there are looming engineering challenges in the second phase front end designs. For instance, in the second phase, a 4.8meter-long 3.3-cm period Undulator A operating at $250 \mathrm{~mA}, 7.5 \mathrm{GeV}$ will provide 22.8-kW total power with $2.8 \mathrm{~kW} / \mathrm{mm}^{2}$ peak heat flux at the first photon shutter location. Furthermore, a 4.8-m Wiggler A may generate $44-\mathrm{kW}$ total power. A significant research and development effort will be needed in materials, thermalhydraulics, surface and interfacial phenomena to meet the design challenges of the second phase beamline front end components.

\section{Acknowledgments}

Thanks are due to the rest of the APS XFD Beamline Engineering and Construction Group staff. Research supported by the U. S. Department of Energy BES Materials Science under Contract W-31-109-ENG-38. 


\section{References}

[1] D.Shu, J. Barraza, T. Sanchez, R. W. Nielsen, J. T. Collins, and T. M. Kuzay, Nucl. Instrum. and Meth. A319 (1992) 63-70.

[2] U. Hahn, D. Shu, and T. M. Kuzay, ANL/APS LS-187, Feb. 1993.

[3] J. Barraza, D. Shu, and T. M. Kuzay, 8-th National Conference on SRI, NIST, Aug. 1993.

[4] D. Shu, H. L. T. Nian, Z. Wang, J. Collins, D. Ryding, and T. M. Kuzay, SPIE Vol.1739 (1992) 218-229.

[5] D. Shu, B. Rodricks, J. Barraza, T. Sanchez, and T. M. Kuzay, Nucl. Instrum. and Meth. 319 (1992) 56-62.

[6] B. Lai and F. Cerrina, Nucl. Instrum. and Meth. A246 (1986) 337.

[7] S. Xu and R. W. Nielsen, SPIE Vol.1739 (1992)346-348.

[8] B. Lai, A. Khounsary, R. Savoy, L. Moog, and E. Gluskin, ANL/APS TB-3, Feb. 1993.

[9] B. Lai, A. Khounsary, and E. Gluskin, ANL/APS TB-11, Feb. 1993.

[10] D. Shu, T. Sanchez, and T. M. Kuzay, ANL/APS LS-192, April 1992.

[11] J. Chang, D. Shu, S.L.T. Nian, J. Collins, D. Ryding, and T. M. Kuzay, to be presented on the High Heat Flux Engineering Conference, SPIE, July, 1993. 


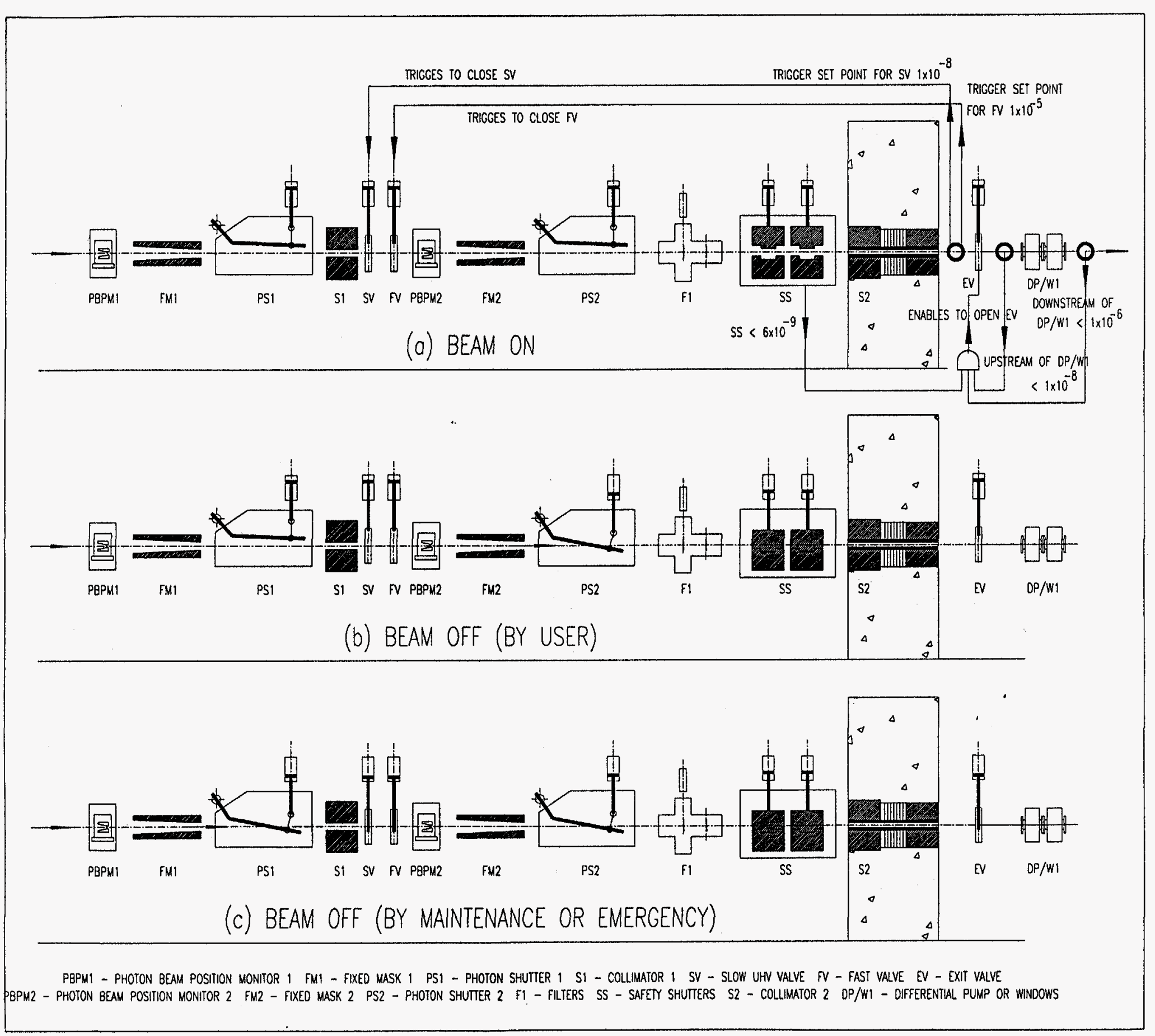




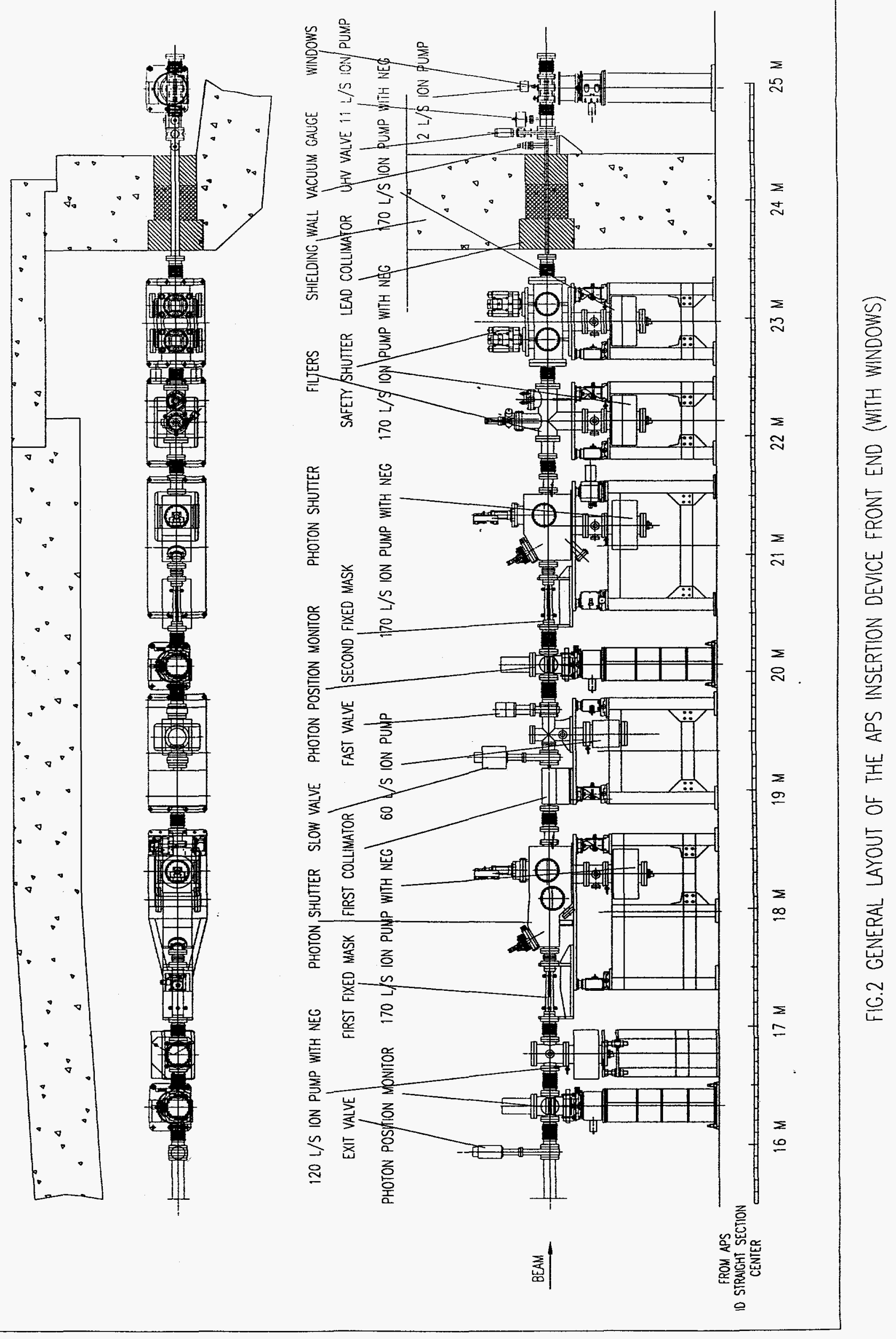




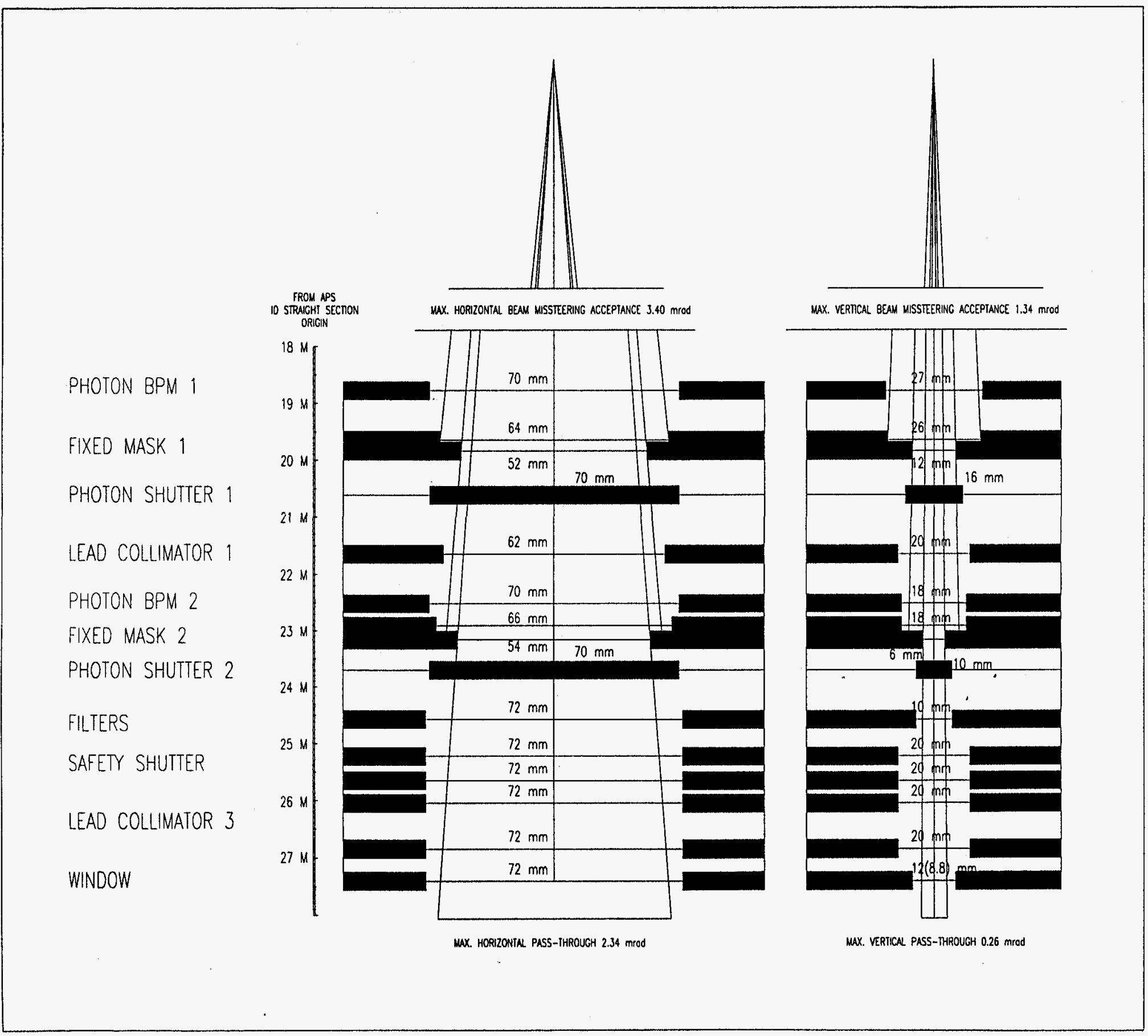

FIG.3 APS ID FRONT END OPTICAL APERTURES 


\section{PHOTON BPM 1}

\section{FIXED MASK 1}

PHOTON SHUTTER 1

LEAD COLLIMATOR 1

PHOTON BPM 2

FIXEO MASK 2

PHOTON SHUTTER 2

\section{FILTERS}

SAFETY SHUTTER

LEAD COLLIMATOR 3 WINDOW

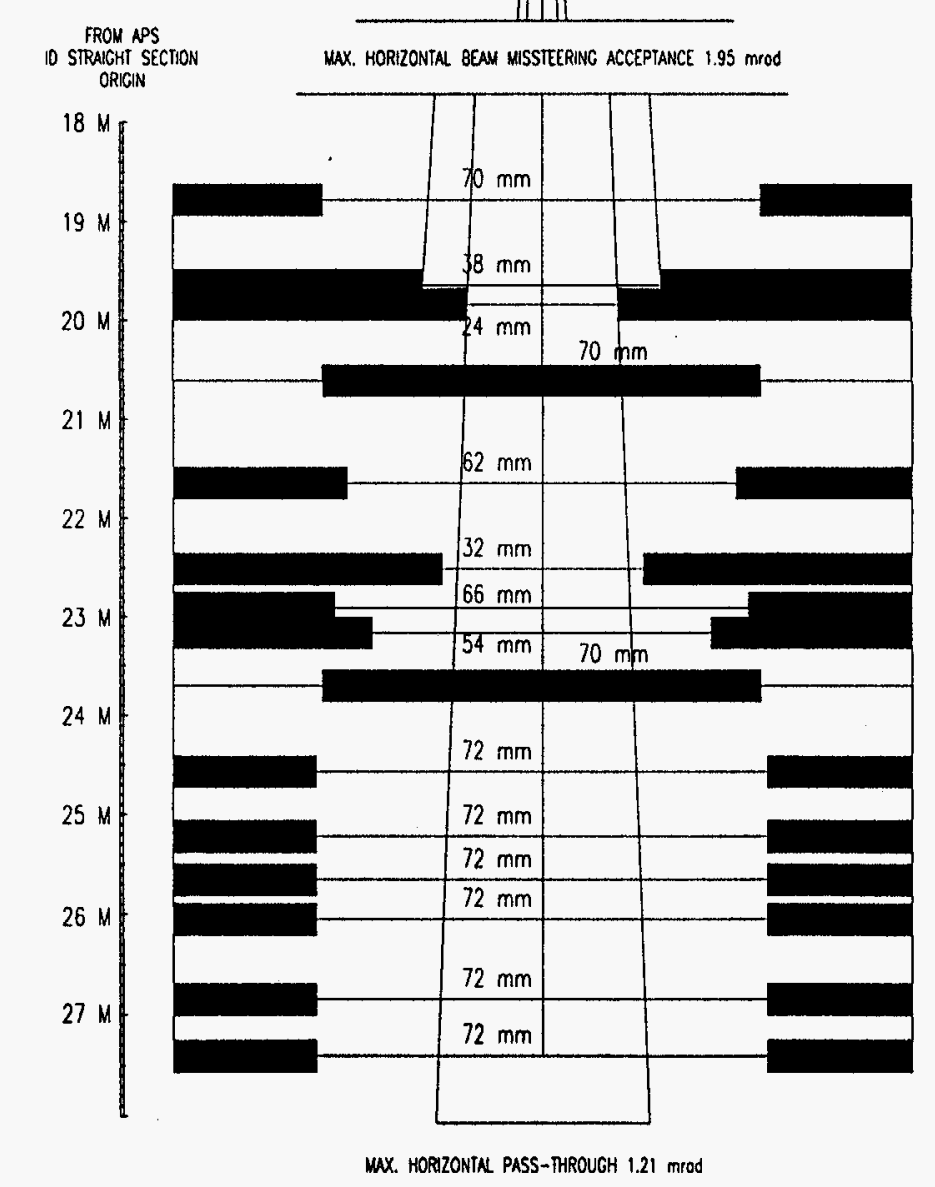

MAX. VERICAL BEAM MISTTERRING ACCEPTANCE 1.34 mrod

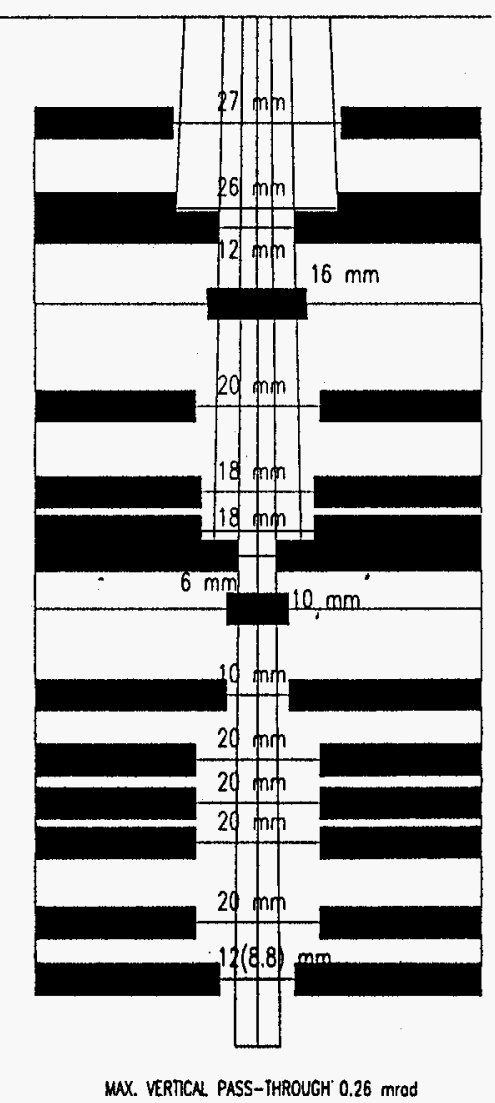

FIG.4 OPTICAL APERTURES FOR APS UNDULATOR FRONT END 


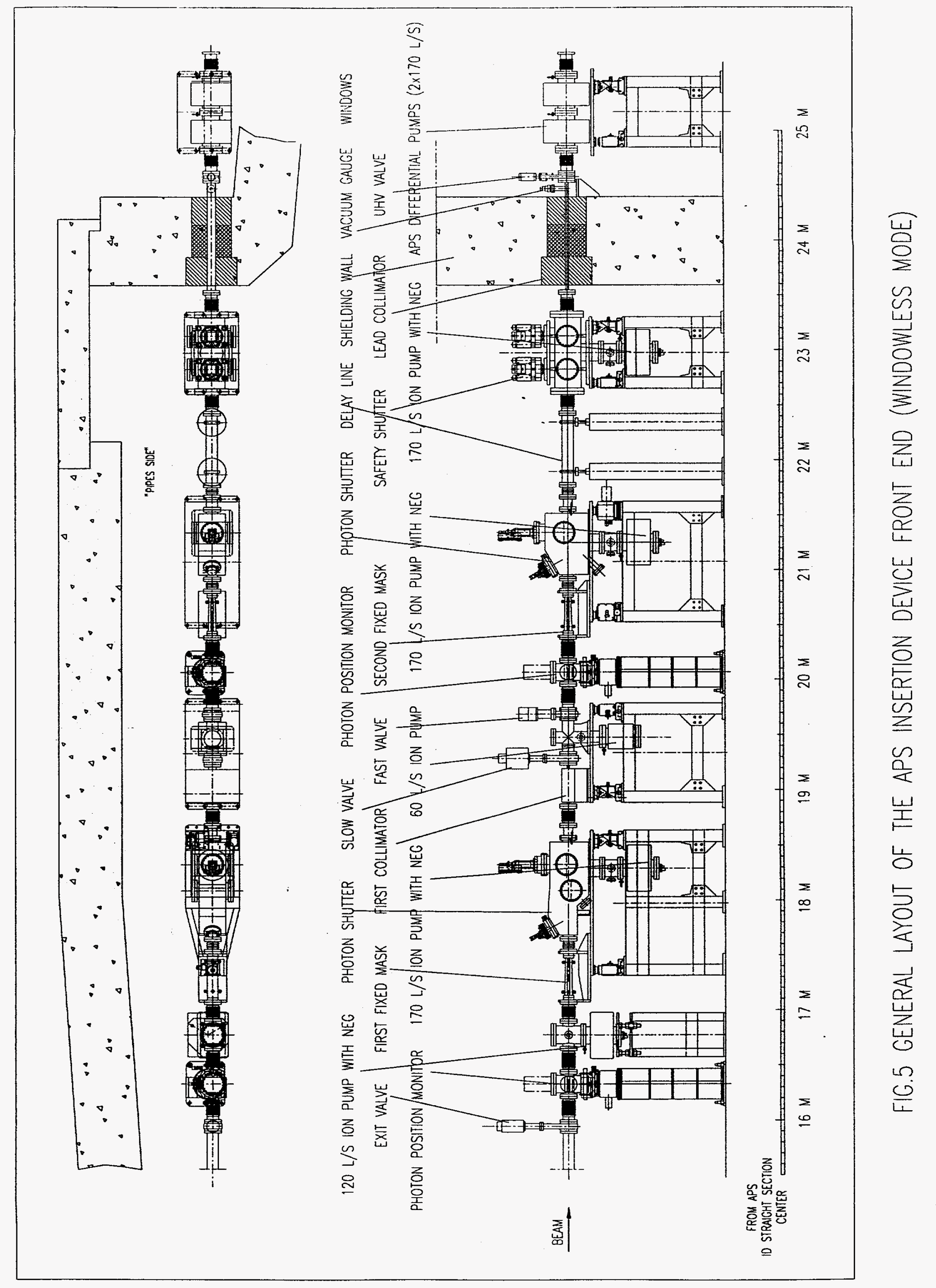



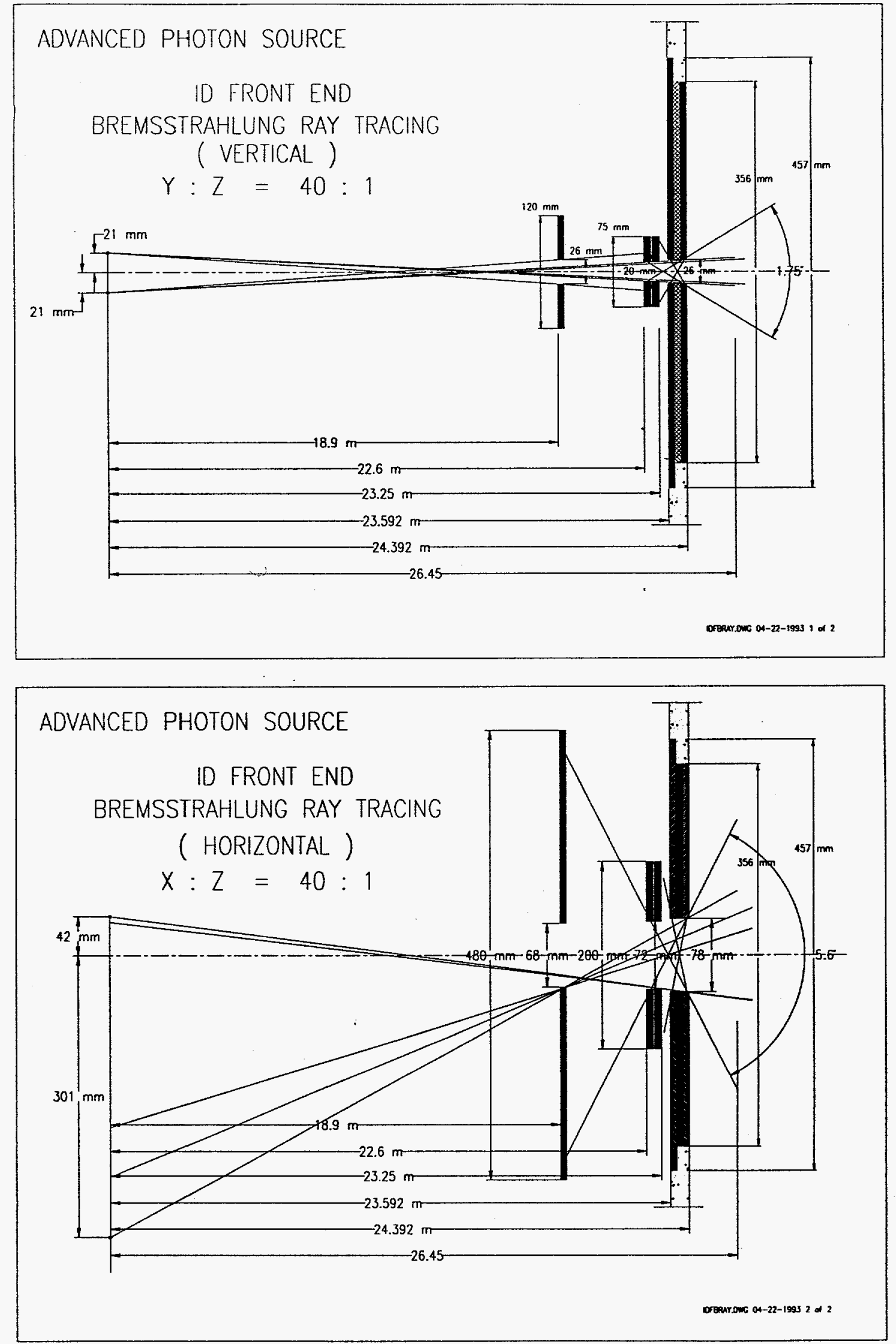


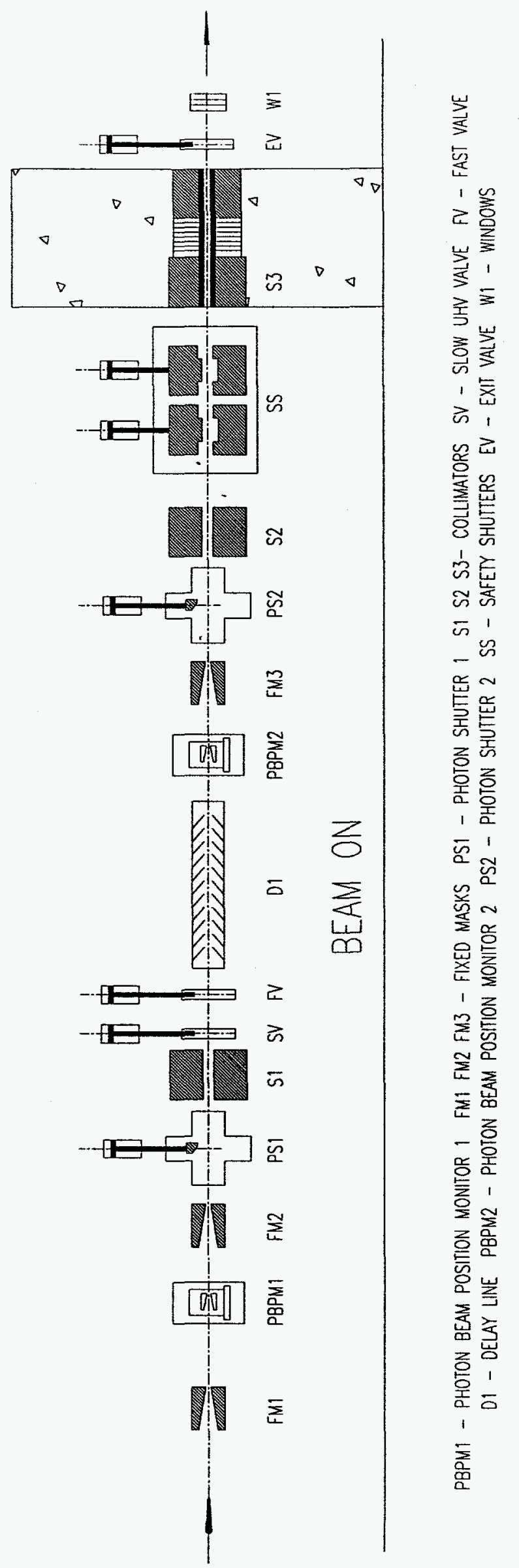




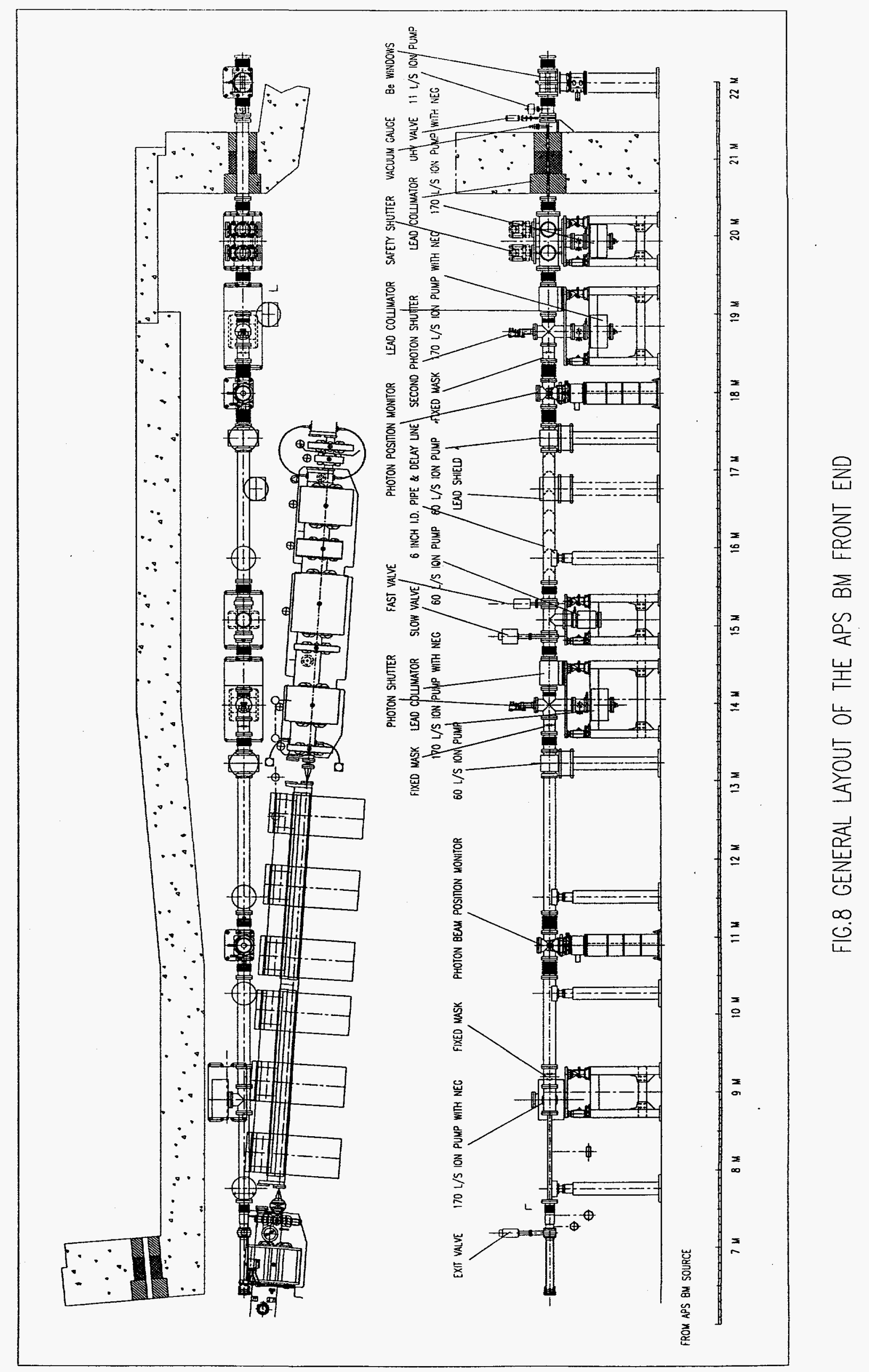


Figure Captions

Fig. 1 Schematic of APS ID front end

Fig.2 General layout of the APS insertion device front end (with windows)

Fig.3 APS ID front end optical apertures

Fig.4 Optical apertures for APS undulator front end

Fig.5 General layout of the APS insertion device front end (windowless mode)

Fig.6 Bremsstrahlung radiation ray-tracing schematic for APS ID front end

Fig.7 Schematic of APS BM front end

Fig. 8 General layout of the APS BM front end 